\title{
A COMPLEXIDADE DO RACISMO ESTRUTURAL: REDUÇÃO DE TRABALHADORES À CONDIÇÃO ANÁLOGA A DE ESCRAVOS COMO CONTINUÍSMO DO SISTEMA ECONÔMICO ESCRAVOCRATA
}

\author{
Herena Neves Maués Corrêa de Melo ${ }^{1}$
}

Resumo:

O objetivo é discernir as bases do racismo estrutural no Brasil, a fim de compreendermos porque o trabalho escravo contemporâneo no Brasil deve ser enfrentado a partir desta lógica, no escopo de que se sua mitigação ocorra de forma sustentável. A metodologia é de caráter qualitativo e exploratório, a partir das nuances da revisão bibliográfica e documental. Percebe-se o racismo estrutural como a fonte causal da normalização da prática de reduzir trabalhadores à condição análoga a de escravos e da reprodução e florescimento da prática, havendo a necessidade de modificação escalonada de ações que envolvam políticas públicas institucionais e educacionais.

Palavras-chave: racismo estrutural; trabalho escravo contemporâneo; normalização social; culturalismo; políticas públicas

\section{THE COMPLEXITY OF STRUCTURAL RACISM: REDUCTION OF WORKERS TO THE CONDITION ANALOGOUS TO THAT OF SLAVES AS CONTINUISM OF THE SLAVE ECONOMIC SYSTEM.}

\begin{abstract}
:
The objective is to discern the bases of structural racism in Brazil, in order to understand why contemporary slave labor in Brazil must be faced from this logic, in the scope that if its mitigation occurs in a sustainable way. Methodology is qualitative, based on the nuances of the bibliographic and documentary review. Structural racism is perceived as the causal source of the normalization of the practice of reducing workers to the condition analogous to that of slaves and the reproduction and flowering of the practice, with the need for staggered modification of actions involving institutional and educational public policies.
\end{abstract}

Keywords: structural racism; contemporary slave labor; social normalization; culturalism; public policies.

\section{Introdução}

A escravidão no Brasil iniciou-se por volta da década de 1530, quando os portugueses implantaram as bases para a colonização da América portuguesa, para atender,

1 Doutora em Administração (Gestão do Desenvolvimento - PPAD- UNAMA); Doutoranda em Desenvolvimento Sustentável do Trópico Úmido ( NAEA- UFPA); Mestra em Direitos Humanos (PPGDUFPA); Promotora de Justiça do Ministério Público do Estado do Pará. Email: herena1983@ gmail.com 
mais especificamente, à demanda dos portugueses por mão de obra para o trabalho na agricultura, foi o modo de produção a mão de obra escarva. Tal processo deu-se, primeiramente, com a escravização dos indígenas, e, ao longo dos séculos XVI e XVII, essa foi sendo substituída pela escravização dos africanos, trazidos por meio do tráfico negreiro.

A escravidão no Brasil, demostrou-se uma criação perversa e cruel, e as suas consequências ainda estão enraizadas na sociedade e duramente sentida no abismo de desigualdade entre as classes sociais. Assim, mais de 130 anos depois que a Lei Áurea aboliu a prática escravocrata juridicamente, a violência e a discriminação que os pretos e pardos sofrem atualmente são o reflexo direto de um país que se construiu por meio da normalização do preconceito e da violência para com esse grupo e para com seus herdeiros da escravidão.

Verifica-se o preconceito estrutural em relação aos pretos e pardos, não somente caracterizados na cor, mas inclusive na captura de sua subjetividade no trabalho escravo contemporâneo, bem como firmando as bases para a admissão da escravização de outras categorias sociais, também vulnerabilizadas, como de imigrantes, índios, mulheres transexuais e crianças.

O objetivo deste artigo é discernir as bases do racismo estrutural no Brasil, a fim de compreendermos porque o trabalho escravo contemporâneo no Brasil deve ser enfrentado a partir desta lógica, a fim de que se sua mitigação ocorra de forma sustentável, e não apenas a partir de uma repercussão normativa, a qual se demonstra fluida, quando se pensa em repostas legais/regulatórias, as quais se modificam de acordo com bases ideológicas governamentais, como se teve no exemplo da modificação da redação da EC n.81/2015 e da proibição no governo Temer da "lista suja" dos empregadores que praticaram o trabalho escravo no final de 2017, a qual virou uma questão judicializada, que somente teve a constitucionalidade confirmada em setembro de 2020 .

Assim, para além da indignação dos estudos acadêmicos sobre a temática do trabalho escravo contemporâneo, percebe-se aceitabilidade e normalização por parte da sociedade e dos seus representantes no que tange a perpetuação de condições indignas de trabalho, quando se põe em relevo os caracteres da redução à condição análoga a de escravos, previstas no Art. 149 do Código Penal Brasileiro.

A metodologia utilizada para o alcance dos resultados é de caráter qualitativo e exploratório, a partir das nuances da revisão bibliográfica e documental sob a égide da análise crítica do conteúdo, pelaqual se obtempera na seguinte pergunta de pesquisa: em que 
medida o racismo estrutural é fator de perpetuação do que se compreende por trabalho escravo contemporâneo?

Segundo a Organização Internacional do Trabalho (OIT, 2009), a escravidão contemporânea é parte da economia mundial e sustenta a produção de uma gama de produtos. A problemática revela aspectos nefastos da globalização da produção e do consumo. Isso porque, por um lado, poucas empresas, governos ou organizações não governamentais se engajam ou reconhecem a problemática do trabalho escravo contemporâneo como uma situação central, admitindo-a apenas como um atributo periférico, sintomático, ou mesmo entendido como metáfora (BALES, 2004; SAKAMOTO, 2008)..

Ainda com com dados da OIT (2017),

O trabalho forçado é um fenômeno global e dinâmico, que pode assumir diversas formas, incluindo a servidão por dívidas, o tráfico de pessoas e outras formas de escravidão moderna.

Ele está presente em todas as regiões do mundo e em todos os tipos de economia, até mesmo nas de países desenvolvidos e em cadeias produtivas de grandes e modernas empresas atuantes no mercado internacion al.

Acabar com o problema exige não só o comprometimento das autoridades dos govern os, como ta mbém um engajamento multifacetado de trabalhadores, empregadores, organismos internacion ais e sociedade civil.

O trabalho escravo contemporâneo está inserido nas relações de mercado entre organizações globais e seus fornecedores, e abrange práticas de gestão de pessoas que fustigam a dignidade humana e os direitos humanos, com o cerceamento da liberdade, a violência física e psicológica, as condições degradantes de trabalho e as jornadas exaustivas de trabalho.

\section{O racismo estrutural}

O racismo estrutural é a construção estabelecida formalmente e institucionalmente a partir de uma série de práticas históricas, culturais e interpessoais no seio de uma sociedade, a qual impõe diferenças entre grupos sociais, de modo exaltar as características de sucesso de um dos grupos, em detrimento dos demais grupos, o quais sofrem prejuízos reais no contexto de participação na construção de suas individualidades e influencia direta no todo social, durante período de tempo significativo. O racismo estrutural também é chamado de racismo social. 
O think tank Aspen Institute (2016, p.01)define o racismo estrutural como:

\begin{abstract}
"Um sistema no qual políticas públicas, práticas institucionais, representações e outras normas funcionam de várias maneiras, muitas vezes reforçando, para perpetuar desigualdade de grupos raciais identificando dimensões de nossa história e cultura que permitem privilégios associados à "brancura" e desvantagens associadas à "cor" para suportar e adaptar ao longo do tempo. O racismo estrutural não é algo que poucas pessoas ou instituições optam praticar mas uma característica dos sistemas sociais, econômicos e políticos em que todos nós existimos."
\end{abstract}

O termo foi pensado para auxiliar as pessoas que trabalham em prol da equidade racial a enfatizar a ideia de que o racismo na sociedade é uma organização sistemática em pleno funcionamento, com uma estrutura clara e com uma plêiade de elementos c.

O autor e diretor-presidente do Instituto Luiz Gama, Silvio Luiz de Almeida, em seu livro Racismo Estrutural (2018) afirma que o racismo não é um ato ou um conjunto de atos e tampouco se resume a um fenômeno restrito às práticas institucionais; é, sobretudo, um processo histórico e político em que as condições de subalternidade ou de privilégio de sujeitos racializados é estruturalmente reproduzida ${ }^{[6]}$ e que considerar o racismo como parte da estrutura não exime a responsabilidade das pessoas em combater o racismo:

[...] pensar o racismo como parte da estrutura não retira a responsabilidade individual sobre a prática de condutas racistas e não é um álibi para racistas. Pelo contrário: entender que o racismo é estrutural, e não um ato isolado de um indivíduo ou de um grupo, nos torna ainda mais responsável pelo combate ao racismo e aos racistas. (ALMEIDA, 2018, p.15)

Para referido autor, são três, as principais concepções do racismo, o racismo individual, que trata o racismo como uma ação do indivíduo que pode ter um problema psicológico, comportamental etc, o racismo institucional, que considera o racismo apenas o resultado de um mau funcionamento das instituições; e por fim, o terceito, denominado de racismo estrutural que tem o racismo como normalidade, o qual pode funcionar como ideologia e/ou como uma prática de naturalização da desigualdade.

Para empresas e instituições, Almeida (2018, p.35) recomenda

adotar políticas antidiscriminatórias permanentes e instituir mecanismos que estabeleçam questionamentos às práticas sociais vigentes nas empresas. Elas não são obrigadas a reproduzir o mundo como ele é. Elas podem melhorá-lo, ofertando coisas que concorrentes não ofertam. Isso só acontece se forem capazes de mudar a forma como estabelecem o relacionamento com o público e suas campanhas de publicidade. 
No Brasil, as causas do racismo estrutural estão associadas, à longa manutenção da escravização dos povos africanos e a tardia abolição da escravidão, a qual planificou as bases do racismo estrutural, considerando que os escravos libertos foram invisibilizados formalmente na construção das políticas públicas e reconhecimento de direitos, deliberadamente excluídos pelo poder público gestor, seja monárquico, seja republicano, do acesso à terra, à educação e ao mercado de trabalho, resultando em um sistema de marginalização que perdura até hoje.

\section{O Trabalho Escravo Contemporâneo}

Ainda que o sistema escravocratajuridicamente aceito tenha findado, deve ser ressaltado como um modelo de produção institucionalizado de forma mundial, à época pelas principais nações com forte potencial comercial e tal fato também se relaciona com, o que se denomina, como trabalho escravo contemporâneo, pois este, apesar de ilegal na maioria das nações, continua sustentando as economias em bilhões de dólares, em todo o mundo.

Sobre o trabalho escravo contemporâneo no meio rural, este pode ser qualificado como o resultado de disparidades socio-econômicas existente entre as regiões do Brasil, por exemplo, os estados do Maranhão e Piauí, são fornecedores de mão-de-obra escrava, e regiões no sul e sudeste do Pará e norte do Mato Grosso, onde os proprietários de terra são pragmáticos e práticos o suficiente para adotarem, ainda hoje, formas pré-capitalistas de produção, como se pode verificar no gráfico abaixo, formatado com dados da Comissão Pastoral da Terra e Ministério do Trabalho e Emprego, que demonstra onde se deram os resgates de trabalhadores escravos e a naturalidade destes trabalhadores.

Convém realizar que o aparato legal brasileiro trata de "condições análogas à de escravo", com base no qual os vários acordos de parcerias têm sido realizados e as penalidades foram definidas. A Lei $\mathrm{n}^{\circ}$ 10.803, de 11 de dezembro de 2003, altera o artigo 149 do Decreto-lei n ${ }^{\circ} 2848$ de 07 de dezembro de 1940, criminaliza a conduta de reduzir pessoas à condição análoga a de escravos, aduzindo que o trabalho escravo contemporâneo se caracteriza legalmente em "reduzir alguém à condição análoga à de escravo, quer submetendo-o a trabalhos forçados ou a jornada exaustiva, quer sujeitando-o a condições degradantes de trabalho, quer restringindo, por qualquer meio, sua locomoção em razão de dívida contraída com o empregador ou preposto". 
Reforçando que as origens e as formas do cerceamento de liberdade dos trabalhadores são diversas, indo desde o isolamento geográfico até comportamentos ameaçadores dos empregadores. Elas envolvem, grosso modo, aspectos ligados ao local, transporte e alimentação.

O trabalho ocorre em locais de difícil acesso, cujo custo de transporte normalmente é caro e debitado aos trabalhadores; a intermediação entre o trabalhador e o empregador é feita por pessoas inescrupulosas, conhecidas como "gato"; a alimentação, comprada em armazéns dos proprietários das fazendas a preços elevadíssimos, reproduzindo o antigo sistema de aviamento. Estas aquisições transformam-se em dívidas crescentes, as quais se acumulam com o pagamento da viagem e dos instrumentos de trabalho e proteção, que deveriam ser fornecidos pelo patrão.

As atividades desenvolvidas pelos trabalhadores são árduas, associadas às condições degradantes, visto que, geralmente, os trabalhadores moram em barracos ou em alojamentos comunitários, cujas condições de higiene são as piores possíveis. O acesso à informação como um dos direitos à cidadania é elemento fundamental da prática governamental.

A redemocratização da sociedade envolve a transparência deste conhecimento, o que inclui a análise dos dados, ainda que qualitativamente. Ao estabelecer correlações entre dados do trabalho escravo (condições de vida do trabalhador, suas condições sociais, tipos de atividades econômicas exercidas, violências e assassinatos), detectamos as principais estruturas do trabalho escravo no Brasil, fornecendo com fundamento em três casos concretos, a influência moderadora da regulação estatal na gestão das políticas públicas que podem levar ao fomento ou mitigação da escravidão contemporânea.

Neste sentido, em última análise, é a formatação de uma modalidade de superexploração do trabalho humano, atualmente reconhecida nos países inseridos na economia mundial, modalidade esta que mereceu um constructo de categoria social, denominada de escravidão contemporânea e estruturação de um conceito jurídico ao longo da história em documentos internacionais, haja vista a evolução do direito internacional, cuja uma das características se funda na voluntariedade e convencionalidade. Estas, portanto, essenciais para se compreender a edificação do referido conceito jurídico de "redução à condição análoga à de escravo" previsto no Art. 149 do Código Penal Brasileiro e o conceito sócio-político de "trabalho escravo contemporâneo" adotado pelo Brasil. 
O fato é que no limiar do século XXI, 120 anos depois da abolição formal da escravidão, as denúncias da prática do Trabalho Escravo Contemporâneo continuam a ocupar as manchetes dos meios de comunicação social.

4. À guisa de discussão dos resultados - Trabalhadores reduzidos à condição análoga a de escravo: qual a cor da pele dos trabalhadores resgatados?

O fato é que a cada cinco trabalhadores resgatados em situação análoga à escravidão entre 2016 e 2018, quatro são negros. Pretos e pardos representam 82\% dos 2, 4 mil trabalhadores que receberam seguro-desemprego após resgate. Entre os negros resgatados estão homens (91\%), jovens de 15 a 29 anos (40\%) e nascidos em estados do Nordeste (46\%). O levantamento foi feito pela organização não governamental Repórter Brasil, com base em dados obtidos da Subsecretaria de Inspeção do Trabalho/Ministério da Economia.

Gráfico 01 - Resgatados da escravidão.

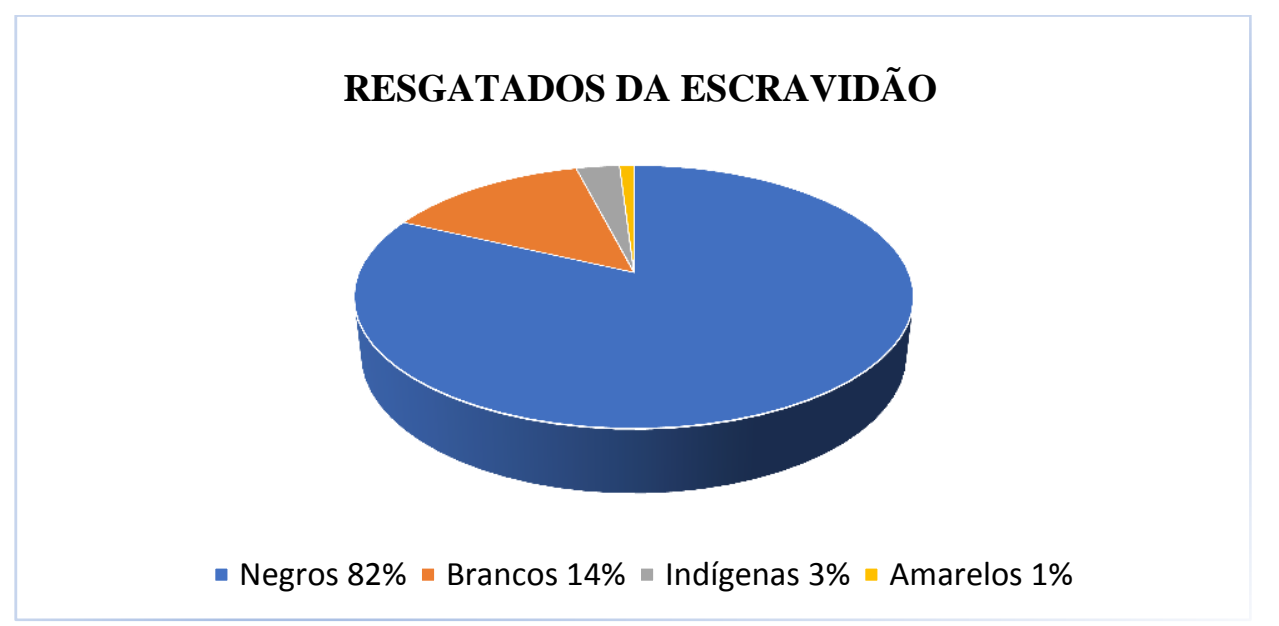

Fonte: Secretaria de Inspeção do Trabalho/Ministério da economia.

O denominado "seguro-desemprego trabalhador resgatado" é um auxílio temporário destinado às vítimas de trabalho escravo. Entre 2016 e 2018, de2.570 trabalhadores resgatados, 2.481 receberam auxílio (96\%), sendo que 343 se autodeclararam brancos e 2.043 negros (soma de pretos e pardos). Os demais se autodeclararam amarelos (18), indígenas (66) ou não fizeram declaração de raça. Os dados da pesquisa vêm do cadastro do segurodesemprego preenchido pelos trabalhadores resgatados pelas operações do Grupo Móvel da Subsecretaria de Inspeção do Trabalho. 
Gráfico 02 - Ocupação dos negros resgatados.

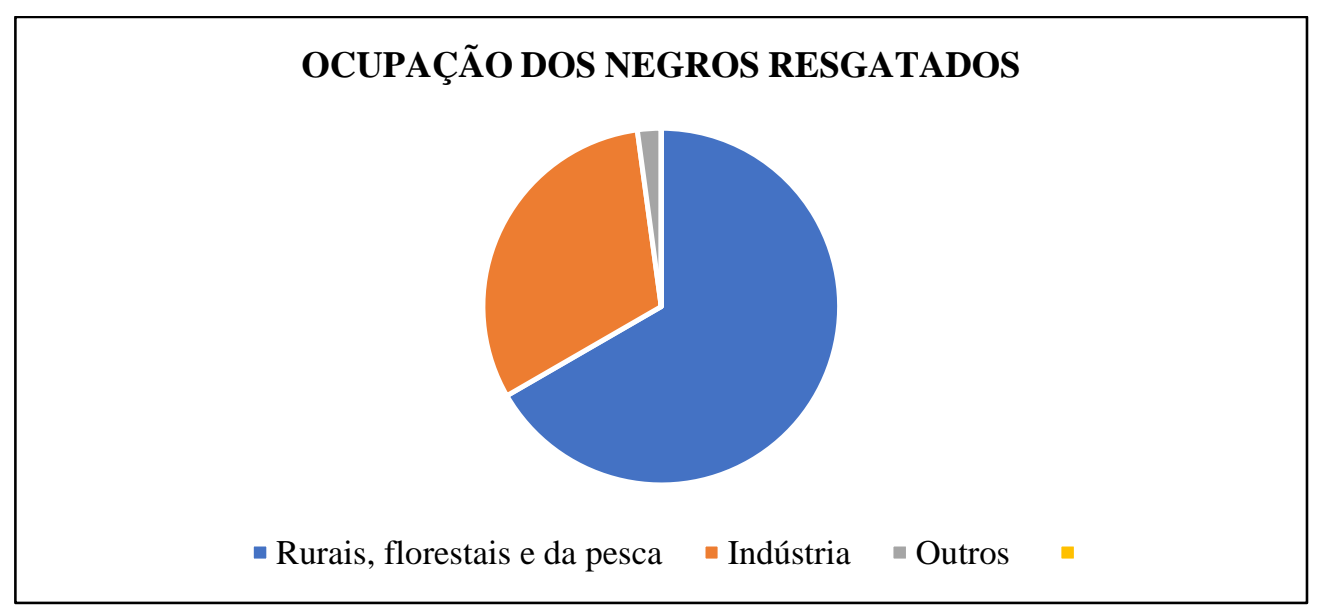

Fonte:Subsecretaria de Inspeção do Trabalho/Ministério da Economia.

Do total de negros resgatados, 62\% eram trabalhadores rurais, florestais e da pesca; $29 \%$ atuavam na indústria. O estudo "Desigualdades Sociais por Cor ou Raça", do IBGE (Instituto Brasileiro de Geografia e Estatística), divulgado no último dia 12 de novembro de 2019, comprova que a população negra representa $64 \%$ dos desempregados e $66 \%$ dos subutilizados, além de ganhar menos do que os brancos.

Gráfico 03 - Perfil da escolaridade dos trabalhadores. 


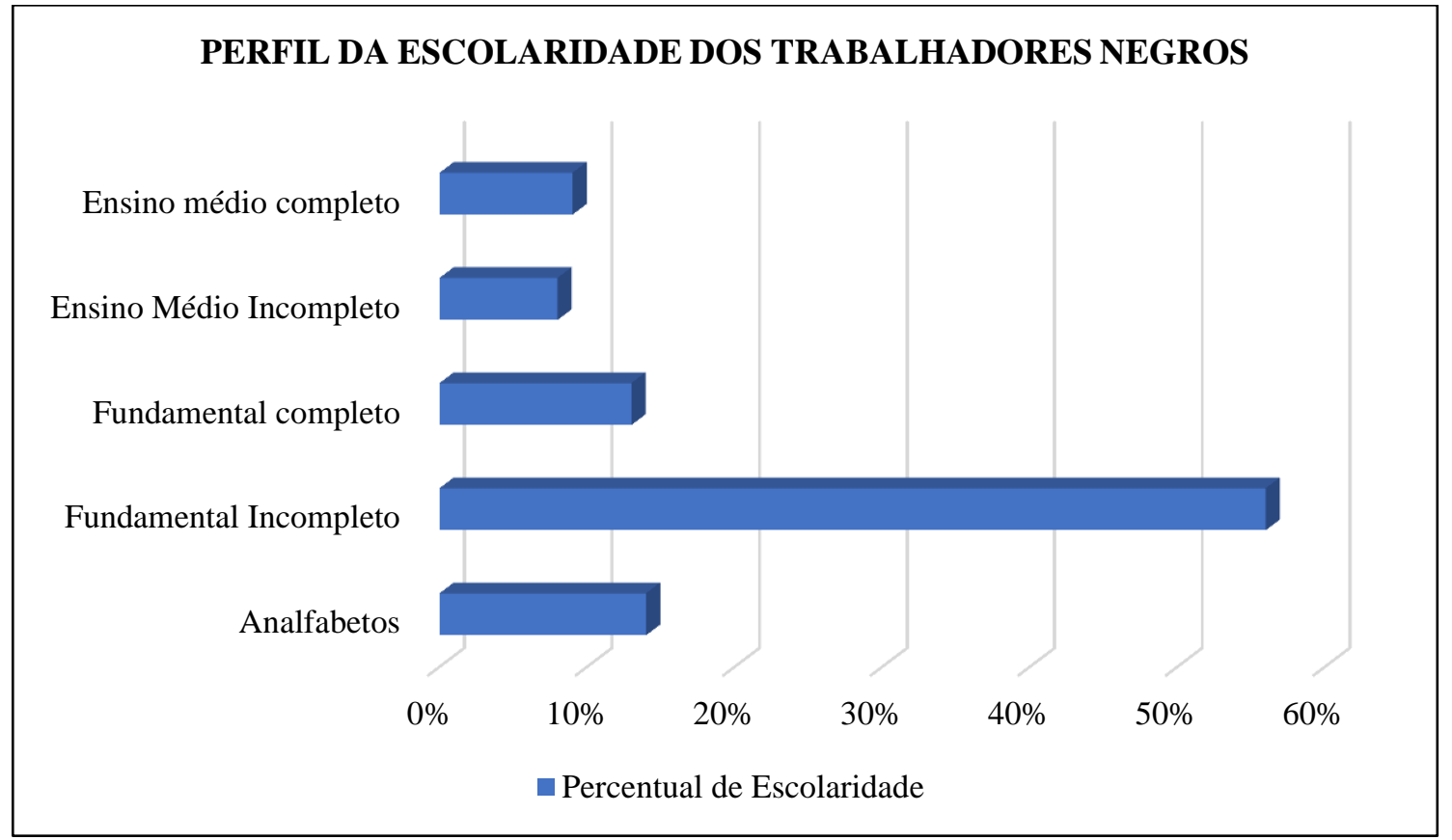

Fonte: Subsecretaria de Inspeção do Trabalho/Ministério da Economia.

Após a análise dos gráficos e a tomada de percepção do contexto vivido pelos negros vitimados pela escravidão contemporânea no Brasil, ressoa a invisibilização da desigualdade, demonstrando-se uma normalização em escravizar negros ou ocupar terras indígenas e quilombolas, conformando-se como socialmente aceitável.

Não obstante, é sempre importante lembrar que, além dos africanos, os indígenas também foram escravizados, pelos portugueses. A escravidão indígena no Brasil existiu principalmente no começo da colonização portuguesa, diminuindo posteriormente por pressão dos lucros do tráfico negreiro. A principal fonte de mão de obra indígena escrava eram as entradas e bandeiras de apresamento, facilitadas pelas desavenças e guerras intertribais dos indígenas brasileiros.

O fato é que sua escravização perpetuou preconceitos e violência contra eles, tanto que a escravidão indígena continua no país. Um exemplo disso é que em 2012 uma forçatarefa do antigo Ministério do Trabalho e Emprego (MTE), do Ministério Público do Trabalho (MPT) e da Funai resgatou 41 indígenas kaingang em condições análogas à de escravo, em Bom Jesus (RS). Eles eram submetidos a condições degradantes no cultivo de maçãs. Entre eles estavam 11 adolescentes de 14 a 16 anos. Os alojamentos estavam em péssimas condições; havia apenas dois banheiros para os 41 trabalhadores; e as famílias, inclusive crianças, se apertavam em um espaço mínimo. Além disso, a fiação elétrica estava solta, o 
frio entrava pelas frestas, a água era armazenada em garrafas pet e havia comida estragada por todo o lugar.

Acerca de uma visão política sobre a escravidão e para diferenciar a escravidão contemporânea brasileira, necessário adentrar no viés sociológico de Florestan Fernandes, que serve de paradigma para a recente discussão de Jessé Souza (2017, 2019), acerca da problemática.

A preocupação de Florestan Fernandes com o problema do negro e da escravidão, a passagem traumatizante do ex-escravo para a condição de homem livre e de cidadão surge quando Florestan Fernandes inicia sua pesquisa com Roger Bastide sobre relações entre brancos e negros em São Paulo em 1951.

A inquietação do presente estudo sobre a escravidão contemporânea brasileira como prática de gestão, tem o intuito de buscar sua contextualização nas raízes da construção histórica e social brasileira para que contribua no pensar do contexto regulatório e provoque uma aplicação qualificada, no que tange à mitigação desta prática no país.

Ainda sobre Florestan Fernandes (1989), este não observava o debate envolvendo os negros como simples tema acadêmico, mas compreendia-o como problemática nacional e para o qual as soluções apresentadas até aquele momento histórico, não ultrapassavam a retórica, e porque não dizer, apoiada em uma ideologia racista subjacente.

Neste ponto está o diferencial entre Florestan Fernandes e os demais cientistas sociais que se ocuparam do tema: ele não via o problema do negro como algo externo à sua existência social, ao contrário nele se integrava, dele se agregava. Essa ligação orgânica entre o cientista e o homem levava-o a procurar a solução política para o problema e nela interferir numa práxis de totalidade entre o cientista, o homem com a sua sensibilidade e o político com suas ferramentas de ação.

Corroborando o acima exposto, Florestan Fernandes (1989, p.49) expõe:

a democracia só será uma realidade quando houver, de fato, igualdade racial no Brasil e o negro não sofrer nenhuma espécie de discriminação, de preconceito, de estigmatização e segregação, seja em termos de classe, seja em termos de raça. Por isso, a luta de classes, para o negro, deve caminhar juntamente com a luta racial propriamente dita. $O$ negro deve participar ativa e intensamente do movimento operário e sindical, dos partidos políticos operários, radicais e revolucionários, mas levando para eles as exigências específicas mais profundas da sua condição de oprimido maior. Ao mesmo tempo o negro deve ter a consciência clara de que sua emancipação coletiva põe o problema da democracia e de uma República democrática sem 
subterfúgios: a revolução dentro da ordem é insuficiente para eliminar as iniquidades, educacionais, culturais, políticas, etc, que afetam os estratos negros e mestiços da população. Mesmo quando o negro não sabe o que é socialismo, a luta por sua liberdade e igualdade possui uma significação socialista. (Grifo de Florestan Fernandes) Daí ser ele uma vanguarda natural entre os oprimidos, os humildes, os explorados, enfim, o elemento de ponta daqueles que lutam por 'um Brasil melhor' ou por uma 'sociedade justa'”.

Por seu turno Jessé Souza (2019), desfoca dos estudos sociológicos distorcidos que pretenderam descrever e entender a construção dos elementos das classes no Brasil sem o debate da escravidão, colocando-a como ponto central de compreensão para o nosso presente e compreensão das bases sociais brasileiras, o entendimento sobre nosso passado e presente escravista.

Para Jessé Souza (2019, p.15) a semente escravista foi silenciada e substituída por uma interpretação cientificamente falsa e politicamente conservadora. Neste ponto, o autor levanta 3 teses, as quais nos permitem iniciar uma reflexão sobre as questões de classe no Brasil, a partir das teorias sociológicas dominantes, as quais excluem do epicentro o passado escravista. Ao silenciar o escravismo (racismo) e optar pelo desenvolvimentismo, os teóricos escamoteiam de que há possibilidade de um país taxado como subdesenvolvido, se desenvolver se seguir um protocolo ou cartilha imposto por outros declarados desenvolvidos.

Assim, se está sob o protótipo teórico da modernização, o qual abriga a clássica percepção da diferença de desenvolvimento entre países, os desenvolvidos dos subdesenvolvidos e agora dos "em desenvolvimento", sendo que este paradigma se traspassa para todos os outros conceitos, categorias ou classes sociais que envolvem a construção de um grau comparativo do que é superior e inferior, melhor e pior.

Assim segue o pensamento dominante da população, sem confrontar e quebrar de fato este raciocínio, de que o Brasil é um país subdesenvolvido, com um povo subdesenvolvido, em termos gerais e em termos específicos gerando essas classificações de subgente, subclasse, subcidade, subpovo para as classes sociais, as quais diretamente possuem algum traço do antigo escravismo brasileiro. Jessé Souza (2019, p.16) esclarece:

As ciências sociais possuem seus paradigmas históricos. Apenas para citar uma modificação mais recente e importante para nossos objetivos, é interessante notar a passagem do paradigma "racista" para o "culturalista" nas ciências sociais. Até a década de 1920, o racismo fenotípico baseado na cor da pela e nos traços fisionômicos era reconhecido como ciência tanto internacional quanto nacionalmente. Era ele que esclarecia, por exemplo, a diferença fundamental de desenvolvimento entre os diversos povos. Pouco a 
pouco, esse tipo de racismo foi criticado e substituído pelo culturalismo. $\mathrm{O}$ culturalismo julgava ter vencido o paradigma racista e tê-lo superado por algo não só cientificamente superior, mas também moralmente melhor.

Jessé de Souza (2019, p.17), leciona ainda:

O instante de ouro do culturalismo foi a entronização da teoria da modernização, produzida especialmente nos Estados Unidos do segundo pós-guerra e disseminada no mundo inteiro. Ela explicava precisamente o porquê de algumas sociedades serem ricas e adiantadas e outras pobres e atrasadas. O Estados Unidos foi, assim, transformado em modelo exemplar para o mundo, e comparações empíricas com outros países foram realizadas em escala massiva para demonstrar que eram o paraíso na Terra e todos os outros países, realizações imperfeitas desse modelo.

O ponto nodal é compreender que o culturalismo se tornou a teoria social das ciências e do senso comum, aceita internacionalmente como uma ideologia e se espraiou nas universidades e espaços públicos que demonstraram aptidão para seu florescimento, em grande parte, os países do ocidente, autodeclarados democráticos e de direito.

\section{Considerações finais}

Neste ponto, em que pese se estar demonstrando as bases para um debate qualificado sobre a escravidão contemporânea no Brasil e seu continuísmo a partir de seu passado escravocrata, como se trata de um trabalho interdisciplinar com foco na contribuição para os estudos em direito, gestão e ciências sociais, parece ser oportuno ressaltar que as bases da gestão tal como se admite cientificamente hoje, nasce nos Estados Unidos, em estudos organizacionais ou estratégias institucionalistas, o que corrobora fundamentalmente a influência do pensamento culturalista e por conseguinte da teoria da modernização, que passa a ser a teoria dominante nas ciências sociais reverberando nas chamadas ciências sociais aplicadas, onde se inclui o direito e a gestão.

Reiterando que no Brasil, a maior quantidade de vítimas de trabalho escravo no Brasil são trabalhadores originários das regiões norte e nordeste, dos estados que se caracterizam por serem os mais pobres, com maiores índices de analfabetismo e de emprego rural: Maranhão, Piauí e Tocantins ${ }^{2}$, entre outros. Os trabalhadores provenientes destes estados se dirigem aos estados com maior demanda de trabalho escravo: Pará, Mato Grosso,

\footnotetext{
2 Relatório da Relatora Especial sobre as formas contemporâneas da escravidão, incluindo suas causas e consequências, Gulnara Shahinian. Missão ao Brasil, 30 de agosto de 2010, pag. 28
} 
Maranhão e Tocantins. As atividades que mais empregam trabalho escravo são a criação de gado, a agricultura em grande escala, o desmatamento e a exploração de carvão. ${ }^{3}$ (GULNARA SHAHINIAN, 2010)

Os trabalhadores, em sua maioria homens pobres, "afrodescendentes ou mulatos", 4 entre 18 e 40 anos de idade, são recrutados em seus estados de origem por "gatos", para trabalhar em estados distantes, com a promessa de salários atrativos. Ao chegarem às fazendas, os trabalhadores são informados de que estão em dívida com seus contratantes por seu transporte, alimentação e hospedagem. Os salários prometidos são reduzidos e não cobrem os custos já assumidos. Em alguns casos, os trabalhadores se endividam cada vez mais, pois têm de comprar tudo o que necessitam nos armazéns das fazendas, a preços elevados. Sua dívida aumenta tanto que nunca podem pagá-la e se veem obrigados a continuar trabalhando.

Os trabalhadores normalmente são vigiados por guardas armados que não lhes permitem sair das fazendas. Caso tentem fugir, normalmente são agredidos. Ademais, a localização geográfica das fazendas pode ser, por si mesma, um elemento que limita a liberdade dos trabalhadores, posto que muitas vezes o acesso a centros urbanos é quase impossível, devido não apenas à distância mas também à precariedade das vias de acesso (MTE, 2011).

Alguns trabalhadores sofrem violações pessoais físicas, sexuais, morais e psicológicas, além de trabalharem em condições que fustigam vida e saúde, anti-higiênicas e de completa degradância. Devido à sua condição de extrema pobreza, sua situação de vulnerabilidade e a necessidade de sobreviver a partir da força laboral desespero, os trabalhadores aceitam as condições de trabalho antes descritas.

No tocante às investigações por estes fatos, de acordo com a OIT, a impunidade da submissão a trabalho escravo se deve à articulação dos fazendeiros com setores dos poderes federais, estaduais e municipais no Brasil. Muitos fazendeiros exercem domínio e influência em diferentes instâncias do poder nacional, seja de forma direta ou indireta.

Em estudos seguintes será importante estudar noções acerca do construto internacional par a escravidão contemporânea, demonstrando que os documentos internacionais, aos quais o Brasil seja signatário influenciam o jogo regulatório apesar das

\footnotetext{
${ }^{3}$ Perícia escrita de Raquel Elias Ferreira Dodge de 18 de fevereiro de 2016

${ }^{4}$ Relatório da Relatora Especial sobre as formas contemporâneas da escravidão, incluindo suas causas e consequências, Gulnara Shahinian. Missão ao Brasil, 30 de agosto de 2010, pag. 29
} 
resistências internas, conforme pode ser delineado na análise documental da aprovação da Emenda Constitucional nº1/2014. Porém, diante da situação brasileira, aqui delimitada, há que se conceber o racismo estrutural como a fonte causal da normalização e aceitação da prática de reduzir trabalhadores à condição análoga a de escravos e portanto, da reprodução e florescimento da prática a partir das instituições, que a deveria combater, seja poder legislativo ou executivo, espraiando-se a ideologia em toda a sociedade, havendo a necessidade de modificação escalonada de ações que envolvam políticas públicas institucionais e educacionais.

Referências Bibliográficas

ALMEIDA, Silvio.Racismo Estrutural. Rio de Janeiro: Pólen Livros, 2018

ARANTES, Paulo de Tarso Lugon. O caso Simone André Diniz e a luta contra o racismo estrutural no Brasil. https://revistades.jur.pucrio.br/index.php/revistades/article/view/264/239. PUC Rio, 2007.

BATISTA, Waleska Migue. A inferiorização dos negros a partir do racismo estrutural Revista Direito Práxis, Rio de Janeiro, Vol. 9, N.4, 2018.

BALES, K. Disposable People: New Slavery in the Global Economy. University of California Press, 2004

BRASIL.Constituição da República Federativa do Brasil.20. ed.São Paulo: Revista dos Tribunais, 2015. RT Legislação.

BRITO FILHO, J. C. M. de. Trabalho com redução do Homen à Condição Análoga à de Escravo e Dignidade da pessoa Humana. Revista Gênesis, Curitiba, n 137, p. 673/682, abr. 2004.

DELMANTO, Celso. Código Penal Comentado. São Paulo: Renovar, 2001.

DEPUTADOS. Camara. Acompanhamento da PEC 438/2001. Disponível em: <http://www.camara.gov.br/proposicoesWeb/fichadetramitacao?idProposicao=36162 > acesso em 01.set.20015.

DOWNS, Anthony. Uma teoria econômica da democracia. São Paulo, Editora da Universidade de São Paulo, 1999.

FAIRCLOUGH, Norman. 1989. Language and Power. Harlow: Longman Group UK Limited.FAIRCLOUGH, Norman. 1995. Critical Discourse Analysis. Harlow: Longman Group UK Limited. 
FIGUEIRA, Ricardo Rezende. Pisando Fora da Própria Sombra: A escravidão por dívida no Brasil contemporâneo. Rio de Janeiro: Civilização Brasileira, 2004.

HIGGINS, Silvio Salej. Fundamentos Teóricos do Capital Social. Chapecó, Editora Argos, 2005.

NACIONAL. Congresso. Parecer n³8, de 2014 às Emendas apresentadas ao Projeto de Lei nº32, de 2013. Disponível em:< http://www.senadofederal.gov.br $>$. Acesso em: 15 de mai. 2015.

BOURDIEU, Pierre, Gostos de classe e estilos de vida. In ORTIZ, R. (org.) Pierre Bourdieu: sociologia. São Paulo: Ática, 1983.

BOMBASSARO, Luiz Carlos. As fronteiras da Epistemologia. 3a. ed. Petrópolis: Vozes, 1993.

FERNANDES. F. Significado do protesto negro. São Paulo: Cortez Editora, 1989.

G. W. F. Hegel. Vida, pensamento e obra de Dr. Gonçal Mayos, trad. Catarina Mourâo, Barcelona: Planeta De Agostini, 2008.

JESSOP, Bob. Nicos Poulantzas: Marxist theory and political strategy. Basingstoke: Macmillan, 1985.

JUNIOR, Eroulths Cortiano. Alguns apontamentos sobre os chamados direitos da personalidade. In: FACHIN, Luiz Edson (Org.). Repensando fundamentos do direito civil brasileiro contemporâneo. 1 ed. Rio de Janeiro: Renovar, 1998, p. 31-56.

JUNIOR, Ataíde Vicente de Paula. O novo juiz e a administração da justiça: repensando a seleção, a formação e a avaliação dos magistrados no Brasil. Curitiba: Juruá, 2006.

LAENDER, Gabriel Boavista. As teorias da regulação e as agências reguladoras no Brasil. Disponível em: <http://moodle.cead.unb.br/agu/mod/folder/view.php?id=485>. Acesso em: 14/03/2018.

LESSA, Sérgio. Para uma ontologia do ser social: um retorno à ontologia medieval? In: ANTUNES, R; LEÃO, R. W. (Orgs.). Lukács: um Galileu no Século XX. 2. ed. São Paulo: Boitempo, 1996, p. 62-73. 
MARTINS, José de Souza. A reprodução do capital na frente pioneira e o renascimento da escravidão no Brasil. Tempo Social; Rev. Sociol. USP, S. Paulo, 6(1-2): 1-25, 1994 (editado em jun. 1995).

MATTOS, Paulo Todescan Lessa. Regulação econômica e social e participação pública noBrasil. In: CONGRESO INTERNACIONAL DEL CLAD SOBRE LA REFORMA DEL ESTADO Y DE LA ADMINISTRACIÓN PÚBLICA, 9, 2004, Madrid. Disponívelem:<https://ipea.gov.br/participacao/images/pdfs/participacao/mattos_regulac ao\%20economica\%20.pdf>. Acesso em: 15.12.2019.

MERINO, Lucyla Tellez. Direito Humanos e Direito do Trabalho: enfoques humanistas na proteção dos direitos sociais. 2006. Dissertação (Mestrado, FD/USP). Ano de defesa 2006.

MIRAGLIA, Lívia Mendes Moreira. Trabalho escravo contemporâneo: conceituação à luz do princípio da dignidade da pessoa humana. 2008. Dissertação (Mestrado) - Pontifícia Universidade Católica de Minas Gerais, Belo Horizonte.

MEIRA, Márcio. A persistência do aviamento: colonialismo e história indígena no Noroeste Amazônico. São Carlos: EdUFSCar, 2018.

MENDES, A. N. Imigrantes em condições análogas a de escravo. Revista do Ministério Público do Trabalho, n 26, set., p.67-70, 2003.

MEURER, Beatrice. O Conteúdo da dignidade humana. In: SARLET, Ingo Wolfgang (Org.). Dimensões da dignidade: ensaios de filosofia do direito e direito constitucional. Porto Alegre: Livraria do Advogado, 2007.

MEYER, J. W.; ROWAN, B. Institutionalized organizations: Formal structure as myth and ceremony. American Journal of Sociology. v 83, p. 340-363, 1977.

MEYER, J; ROWAN, B. Institutionalized organizations: formal structure as myth and ceremony. In: DIMAGGIO, P; POWELL, W. (Eds.). The new institutionalism in organizational analysis. Chicago: The University of Chicago Press, 1992. p.1-41.

MIGUEL, Juan Francisco Delgado de. Derecho agrário ambiental: propiedad y e

MUNIR, K. A. A Loss of power in institutional theory. Journal of Management Inquiry, Cambridge, v. 24, n. 1, p. 90-92, May 2015.

SAKAMOTO, Leonardo. Lucro fácil, mão-de-obra descartável a escravidão contemporânea e economia internacional.In: COGGIOLA, Osvaldo. (Org.). América Latina e a Globalização. 1 ed. São Paulo: FFLCH/PROLAM/Universidade de São Paulo, 2004.

SAKAMOTO, Leonardo (Org.).Trabalho escravo no Brasil do século XXI. Brasília : Organização Internacional do Trabalho, 2007.

SCHIMITT, Carl. Teoria de la Constitución. Madrid: Alianza Editorial, 1996. 
SENTO-SÉ, Jairo Lins de Albuquerque. Trabalho Escravo no Brasil, São Paulo: Ltr, 2000.

SHAHINIAN, Gulnara. Relatório da relatora especial sobre as formas contemporâneas da escravidão, incluindo suas causas e consequências. Missão ao Brasil, 30 de agosto de 2010, par. 28

SOUZA, Jessé. A Elite do Atraso: Da Escravidão à Lava Jato, São. Paulo: Editora Leya, 2017.

SOARES, Evanna. Meios coadjuvantes de combate ao trabalho escravo pelo Ministério Público do Trabalho. Revista do Ministério Púbico do Trabalho, n 26, p. 34-46, 2003.

SOUSA, R. ; VOSS, C. A. Contingency research in operations management practices. Journal of Operations Management, New Jersey, NY, v. 26, n. 6, p. 697-713, 03 Oct. 2008.

SOUZA, Paulo Roberto Pereira de. A constitucionalização do direito de propriedade como instrumento de efetividade do Direito Ambiental. São Paulo: Lemos \& Cruz, 2004.

SUSSEKIND, Arnaldo. Convenções da OIT. São Paulo: LTR, 1994.

SUTTON, Alison. Trabalho Escravo: Um elo na cadeia da modernização do Brasil de hoje. São Paulo:CPT, 1992. 